\title{
Sintering Behavior, Microstructure, and Thermal Conductivity of Dense AlN \\ Ceramics Processed by Spark Plasma Sintering with $\mathrm{Y}_{2} \mathrm{O}_{3}-\mathrm{CaO}-\mathrm{B}$ Additives
}

\author{
Ryota Kobayashi* \\ Department of Chemistry and Energy Engineering, Faculty of Engineering, Tokyo City University \\ 1-28-1, Tamazutsumi, Setagaya-ku, Tokyo 158-8557, Japan \\ Tel: +81-3-5707-3811, Fax: +81-3-5707-1171, E-mail: rkobaya@tcu.ac.jp \\ *Corresponding author
}

Katsuyoshi Oh-ishi

Department of Applied Chemistry, Faculty of Science and Engineering, Chuo University

1-13-27, Kasuga, Bunkyo-ku, Tokyo 112-8551, Japan

Rong Tu, Takashi Goto

Institute for Materials Research, Tohoku University

2-1-1, Katahira, Aoba-ku, Sendai 980-8577, Japan

\begin{abstract}
We fabricated dense aluminum nitride ceramics by spark plasma sintering (SPS) with $\mathrm{Y}_{2} \mathrm{O}_{3}-\mathrm{CaO}-\mathrm{B}$ sintering additives and evaluated their microstructures and thermal conductivities. Samples were perfectly densified after 5 min of SPS at 1650 or $1600{ }^{\circ} \mathrm{C}$ or 10 min at $1550{ }^{\circ} \mathrm{C}$ and had fine microstructures. Thermal conductivities of the samples were $80-90 \mathrm{~W} \mathrm{~m}^{-1} \mathrm{~K}^{-1}$ and tended to increase with increasing sintering temperature.
\end{abstract}

Keywords: Aluminum nitride; SPS; Ceramics; Densification; Thermal conductivity 
Aluminum nitride (AIN) ceramics have high thermal conductivity, high electrical insulation, and excellent corrosion resistance to halogens and plasma $[1,2]$. These properties of AlN ceramics favor their use as substrate materials for power electronics and structural parts for semiconductor devices. AlN is a typical sintering resistive non-oxide ceramic; its fabrication involves high-temperature sintering with sintering additives to obtain dense ceramics.

Komeya et al. developed dense AlN ceramics by pressureless sintering (PLS) at $1800{ }^{\circ} \mathrm{C}$ for several hours, using $\mathrm{Y}_{2} \mathrm{O}_{3}$ as a sintering additive [3]. Liquid phases composed of Y-Al-O complex oxides form when the natural oxide layer on AIN particles reacts with $\mathrm{Y}_{2} \mathrm{O}_{3}$, promoting the densification of AlN ceramics. Since then, there has been ongoing research into additives that lower the sintering temperature. By using $\mathrm{Y}_{2} \mathrm{O}_{3}-\mathrm{CaO}$ sintering additives, the temperature can be lowered to $1700{ }^{\circ} \mathrm{C}[4,5]$. The formation of Y-Al-Ca-O complex oxides having low eutectic melting points (around $1600{ }^{\circ} \mathrm{C}$ ) appears to promote densification [6]. Further, the addition of boron or borides such as $\mathrm{LaB}_{6}$ to the $\mathrm{Y}_{2} \mathrm{O}_{3}-\mathrm{CaO}$ system can lower the sintering temperature below $1700{ }^{\circ} \mathrm{C}[7,8]$. We reported that $\mathrm{Y}_{2} \mathrm{O}_{3}-\mathrm{CaO}$-B sintering additives can sinter $\mathrm{AlN}$ ceramics at $1650{ }^{\circ} \mathrm{C}$ in $2 \mathrm{~h}$ [8]; however, when using the PLS process, densification was insufficient at lower temperatures (below $1650^{\circ} \mathrm{C}$ ) and a shorter sintering time $(1 \mathrm{~h}$ ).

In recent years, the spark plasma sintering (SPS) process [9], which is also called pulsed electric current sintering (PECS) [10], has been widely used for densification of sintering resistive ceramics such as carbides and nitrides [11-14]. In the SPS process, raw powders are put into a mold fabricated from an electrically conductive 
material such as graphite and then quickly heated by supplying a large pulse of electric current to the mold while applying uniaxial pressure. The fast heating and uniaxial pressure in SPS help mass transfer during densification without abnormal grain growth. Therefore, the SPS process can shorten sintering time and lower sintering temperature. There are several reports on densification of AlN ceramics by SPS. Khor et al. successfully fabricated dense AlN ceramics with thermal conductivities of $70-95 \mathrm{~W} \mathrm{~m}^{-1}$ $\mathrm{K}^{-1}$ by $1-2$ cycles of SPS at $1500-1600{ }^{\circ} \mathrm{C}$ with $\mathrm{Sm}_{2} \mathrm{O}_{3}$ sintering additives [15]. In contrast, sintering at $1800{ }^{\circ} \mathrm{C}$ for several hours is necessary for densification by pressureless sintering (PLS) with the same additives, clearly indicating the effects of SPS. Qiao et al. reported fabrication of dense AlN ceramics by SPS without sintering additives at $1600{ }^{\circ} \mathrm{C}$, but the thermal conductivities of the samples were lower than 60 $\mathrm{W} \mathrm{m}{ }^{-1} \mathrm{~K}^{-1}[16]$. These results show that the use of sintering additives is necessary for obtaining fully densified AIN ceramics by the SPS process with favorable thermal conductivity.

In our previous work [8], we fabricated dense AlN ceramics with a thermal conductivity of $95 \mathrm{~W} \mathrm{~m}^{-1} \mathrm{~K}^{-1}$ by PLS at $1650{ }^{\circ} \mathrm{C}$ for $2 \mathrm{~h}$ with $\mathrm{Y}_{2} \mathrm{O}_{3}$-CaO-B additives. If we use both the SPS process and $\mathrm{Y}_{2} \mathrm{O}_{3}-\mathrm{CaO}-\mathrm{B}$ additives, the sintering temperature may be decreased below $1600{ }^{\circ} \mathrm{C}$, as reported by Khor et al [15]. In this work, we fabricate dense AlN ceramics by SPS with $\mathrm{Y}_{2} \mathrm{O}_{3}$-CaO-B additives, and investigate the sintering behavior, microstructures, and thermal conductivities of the samples produced.

\section{Experimental procedure}

Commercially available AlN powder (Tokuyama Corp., Grade-E, $0.6 \mu \mathrm{m}$ ) was used as a raw material. $\mathrm{Y}_{2} \mathrm{O}_{3}$ (Rare Metallic Corp., $99.99 \%$ ), $\mathrm{CaO}$ was produced by 
calcining $\mathrm{CaCO}_{3}$ (Rare Metallic Corp., 99.99\%), and B (Rare Metallic Corp., 97\%) powders were added to the AlN raw powder as sintering additives. Composition of the mixture was 95.92 mass $\%$ AlN, 3 mass $\% \mathrm{Y}_{2} \mathrm{O}_{3}, 1$ mass $\% \mathrm{CaO}, 0.08$ mass $\% \mathrm{~B}$ (named 0.08B). The powder mixtures were ball-milled in butanol for $4 \mathrm{~h}$ using $\mathrm{ZrO}_{2}$ balls ( $\phi: 5$ $\mathrm{mm})$. The slurry was dried using a rotary evaporator, then sieved with $212-\mu \mathrm{m}$ Nylon mesh to form granules. The granules were put into a graphite mold $(\phi: 10 \mathrm{~mm})$ lined with graphite sheet and covered with carbon fiber insulation felt, then sintered using an SPS system (Sumitomo Coal Mining Co., Ltd., Dr. Sinter SPS-1050) under 1 atm $\mathrm{N}_{2}$. Heating rates were $200{ }^{\circ} \mathrm{C} / \mathrm{min}$ from room temperature to $600{ }^{\circ} \mathrm{C}$, then $100{ }^{\circ} \mathrm{C} / \mathrm{min}$ from $600{ }^{\circ} \mathrm{C}$ to the holding temperature. For sintering temperatures of $1550{ }^{\circ} \mathrm{C}$ and $1650{ }^{\circ} \mathrm{C}$, the heating rate was decreased to $50{ }^{\circ} \mathrm{C} \min ^{-1} 1$ min before the holding temperature due to limitations in setting the heating profiles. The holding temperatures and times were $1550{ }^{\circ} \mathrm{C}$ for $10 \mathrm{~min}, 1600{ }^{\circ} \mathrm{C}$ for $5 \mathrm{~min}$, and $1650{ }^{\circ} \mathrm{C}$ for $5 \mathrm{~min}$. A constant uniaxial pressure of $50 \mathrm{MPa}$ was applied during the SPS process. After holding, the power supply of the SPS apparatus was shut down and the uniaxial pressure released immediately. The change in the relative density during SPS was estimated from the press displacement by using the method described in the previous paper [14].

Densities of samples were measured at room temperature by Archimedes' method using pure water as buoyancy fluid. Phase identification and elemental analyses of samples were carried out by X-ray diffraction (XRD) with CuKa radiation and X-ray fluorescence (XRF), respectively. Microstructures of the samples were evaluated by scanning electron microscopy (SEM). Thermal conductivities of the samples were measured at room temperature by laser flash method. 
Table 1 lists relative densities of the SPS samples in this work and the PLS samples from our previous work [8]. For comparison, the relative densities of the samples sintered using $\mathrm{Y}_{2} \mathrm{O}_{3}-\mathrm{CaO}$ sintering additives without $\mathrm{B}$ (named $0 \mathrm{~B}$ ) are also listed. The relative densities of the SPS samples were over $99 \%$ of theoretical values, indicating perfect densification even with very short sintering time. In contrast, densities of the PLS samples were drastically decreased by lowering the sintering temperature. In the PLS samples, 0.08B samples had higher relative densities than 0B samples specifically in the sample sintered at $1600^{\circ} \mathrm{C}$. These results clearly show the effect of the SPS process on densification of AlN ceramics sintered with $\mathrm{Y}_{2} \mathrm{O}_{3}-\mathrm{CaO}-\mathrm{B}$ additives.

Figure 1 shows the shrinkage curves of the SPS samples at $1550-1650{ }^{\circ} \mathrm{C}$. For comparison, the shrinkage curves of the SPS samples sintered using $\mathrm{Y}_{2} \mathrm{O}_{3}-\mathrm{CaO}$ sintering additives without $\mathrm{B}(\mathrm{OB})$ are also shown. The vertical axis indicates the change of relative density, calculated from the press displacement during SPS and the final density of the sample (Table 1) [14]. The lower and upper horizontal axes indicate temperature rising and elapsed time at the holding temperatures, respectively. In all samples, the sintering shrinkage started around $1300{ }^{\circ} \mathrm{C}$ and accelerated above $1500{ }^{\circ} \mathrm{C}$. In the SPS samples at $1550{ }^{\circ} \mathrm{C}$, relative density had reached $80 \%$ of its theoretical value by the beginning of the holding stage, and densification was almost complete after 5 min. The degree of shrinkage increased between 1500 and $1550{ }^{\circ} \mathrm{C}$ due to the decrease of heating rate. In the SPS sample held at $1600{ }^{\circ} \mathrm{C}$, the relative density also approached $80 \%$ of theoretical by the start of holding and achieved almost $100 \%$ of theoretical after 2 min, similar to the SPS sample at $1550{ }^{\circ} \mathrm{C}$. In the SPS sample at $1650{ }^{\circ} \mathrm{C}$, the relative density was drastically increased over $1600{ }^{\circ} \mathrm{C}$, and the densification was almost completed at 
the start point of holding time. A comparison of the shrinkage curves of the samples sintered using $0.08 \mathrm{~B}$ and $\mathrm{OB}$ sintering additives showed that the densifications of samples sintered with $0.08 \mathrm{~B}$ were slightly faster than those of $0 \mathrm{~B}$. These results show that a sintering temperature of $1550{ }^{\circ} \mathrm{C}$ was high enough to achieve perfect densification, and it might be possible to lower the sintering temperature below $1550{ }^{\circ} \mathrm{C}$ by increasing the pressure applied and by extending the holding time.

Figure 2 shows the microstructure of the SPS samples in the temperature range 1550-1650 ${ }^{\circ} \mathrm{C}$, investigated by SEM. Fig. 2 (a), (c), and (e) are back-scattered images; Fig. 2 (b), (d), and (e) are the secondary electron images. The secondary electron images show that all the SPS samples have dense and fine textures with a grain size of about 1 $\mu \mathrm{m}$. The AlN powder grains are initially sub-micron in size; therefore, the degree of grain growth during sintering was small. The fast heating rate and high uniaxial pressure of the SPS process may restrain significant grain growth and promote densification in the earlier stages of sintering. The grains in the samples appear angular, suggesting that liquid phases formed during sintering and helped the densification by a solution-precipitation mechanism [17]. The light spots in the back-scattered images indicate the presence of elements heavier than $\mathrm{Al}$ and $\mathrm{N}$, suggesting that the grain boundary phases contain $\mathrm{Ca}$ and $\mathrm{Y}$ derived from the sintering additives. The XRD results show that an $\mathrm{Y}_{4} \mathrm{Al}_{2} \mathrm{O}_{9}$ (YAM) phase and traces of a $\mathrm{CaYAl}_{3} \mathrm{O}_{7}$ phase were detected in all samples as grain boundary phases, similar to the results observed for the PLS samples in our previous work [8]. The liquid phase sintering process appears to be more pronounced with the sintering temperature: the light spots become more clearly defined with increasing sintering temperature, suggesting the enhancement of liquid phase formation, segregation, and crystallization for densification. The uniaxial pressure 
applied during SPS may also promote the liquid phase extruding through grain boundaries.

Figure 3 shows thermal conductivities of the SPS samples, measured by a laser flash method. Thermal conductivities of the SPS samples were in the range 80-90 W $\mathrm{m}^{-1} \mathrm{~K}^{-1}$, comparable to those of the SPS samples investigated by Khor et al. using a $\mathrm{Sm}_{2} \mathrm{O}_{3}$ sintering additive [15] and the PLS samples in our previous work with an $\mathrm{Y}_{2} \mathrm{O}_{3}-\mathrm{CaO}-\mathrm{B}$ additive [8]. The thermal conductivity of the SPS samples in this work tended to increase with increasing sintering temperature. The thermal conductivity of the AlN ceramics could be decreased by the presence of pores, excess grain boundary phases with low thermal conductivities, and oxygen impurities [1] dissolved in the AlN lattice. As these samples are dense ceramics without pores, grain boundary phases and oxygen impurities might affect the thermal conductivity. Applying higher uniaxial pressure and extending the sintering time could reduce the number of grain boundary phases and help in purifying AlN grains to reduce "oxygen trapping by grain boundary phase" $[18,19]$ to improve thermal conductivities.

\section{Conclusions}

The use of $\mathrm{Y}_{2} \mathrm{O}_{3}-\mathrm{CaO}-\mathrm{B}$ sintering additives in the SPS process helps promote densification of AlN ceramics at considerably lower temperatures $\left(1550-1650{ }^{\circ} \mathrm{C}\right)$ and shorter holding times (<10 min). The relative densities of samples became at least $99 \%$ of their theoretical values; the sample textures were dense and fine. The thermal conductivities were in the range $80-90 \mathrm{~W} \mathrm{~m}^{-1} \mathrm{~K}^{-1}$ and increased with increasing sintering temperature. 
This work was partly supported by the Adaptable and Seamless Technology Transfer Program through target-driven R \& D (A-STEP), Japan Science and Technology Agency (JST), Japan (No. AS231Z01267C).

\section{References}

[1] Slack GA, Nonmetallic crystals with high thermal conductivity, J. Phys. Chem. Solid. 34 (1973) 321-335.

[2] Long G, Foster LM, Aluminum nitride: A refractory for aluminum to $2000^{\circ} \mathrm{C}, \mathrm{J}$. Am. Ceram. Soc. 42 (1959) 53-59.

[3] Komeya $\mathrm{K}$, Inoue $\mathrm{H}$, Tsuge A, Effect of various additives on sintering of aluminum nitride, Yogyokyokaishi 89 (1981) 330-336.

[4] Troczynski TB, Nicholson PS, Effect of additives on the pressureless sintering of aluminum nitride between $1500^{\circ} \mathrm{C}$ and $1800^{\circ} \mathrm{C}$, J. Am. Ceram. Soc. 72 (1989) $1488-1491$.

[5] Watari K, Valecillos MC, Brito ME, Toriyama M, Kanzaki S, Densification and thermal conductivity of AlN doped with $\mathrm{Y}_{2} \mathrm{O}_{3}, \mathrm{CaO}$ and $\mathrm{Li}_{2} \mathrm{O}$, J. Am. Ceram. Soc. 79 (1996) 3103-3108.

[6] Watari K, Hwang HJ, Toriyama M, Kanzaki S, Effective sintering aids for low-temperature sintering of AlN ceramics, J. Mater. Res. 14 (1999) 1409-1417.

[7] Kasori M, Sumino H, Horiguchi A, Ueno F, Mechanical and thermal properties of low temperature sintered AlN, Ceram. Trans. 83 (1998) 485-492.

[8] Kobayashi R, Moriya Y, Imamura M, Oosawa K, Oh-ishi K, Relation between oxygen concentration in AlN lattice and thermal conductivity of AlN ceramics 
sintered with various sintering additives, J. Ceram. Soc. Jpn. 119 (2011) 291-294.

[9] Omori M, Sintering, consolidation, reaction and crystal growth by the spark plasma sintering, Mater. Sci. \& Eng. A 287 (2000) 183-188.

[10]Munir ZA, Quach DV, Ohyanagi M, Electric current activation of sintering: A review of the pulsed electric current sintering process, J. Am. Ceram. Soc. 91 (2011) 1-19.

[11]Nishimura T, Mitomo M, Hirotsuru H, Kawahara M, Fabrication of silicon nitride nano-ceramics by spark plasma sintering, J. Mater. Sci. Lett. 14 (1995) 1046-1047.

[12] Ohyanagi M, Yamamoto T, Kitaura H, Kodera Y, Ishii T, Munir ZA, Consolidation of nanostructured SiC with disorder-order transformation, Scr. Mater. 50 (2004) $111-114$.

[13]Kobayashi R, Tatami J, Wakihara T, Komeya K, Meguro T, Goto T, Tu R, Use of post-heat treatment to obtain $2 \mathrm{H}$ solid solution in SPS processed AlN-SiC mixtures, J. Am Ceram. Soc. 91 (2008) 1548-1552.

[14] Kobayashi R, Tatami J, Chen IW, Wakihara T, Komeya K, Meguro T, Goto T, Tu R, High temperature mechanical properties of dense $\mathrm{AlN}-\mathrm{SiC}$ ceramics fabricated by spark plasma sintering without sintering additives, J. Am. Ceram. Soc. 94 (2011) 4150-4153.

[15] Khor KA, Yu LG, Murakoshi Y, Spark plasma sintering of $\mathrm{Sm}_{2} \mathrm{O}_{3}$-doped aluminum nitride, J. Eur. Ceram. Soc. 25 (2005) 1057-1065.

[16]Qiao L, Zhou H, Li C, Microstructure and thermal conductivity of spark plasma sintering AlN ceramics, Mater. Sci. \& Eng. B 99 (2003) 102-105.

[17]Kingery WD, Introduction to Ceramics. John Wiley \& Sons (1960).

[18] Shinozaki K, Tsuge A, Development of high thermal conductive aluminum nitride, 
Ceram. Japan 21 (1986) 1130-1135 (in Japanese).

[19]Virkar AV, Jackson TB, Cutler RA, Thermodynamic and kinetic effects of oxygen removal on the thermal conductivity of aluminum nitride, J. Am. Ceram. Soc. 72 (1989) 2031-2042. 
Table 1 Relative densities* (\%) of SPS and PLS samples.

\begin{tabular}{lcccc}
\hline & \multicolumn{2}{c}{ SPS } & \multicolumn{2}{c}{ PLS } \\
Sintering temperature $/{ }^{\circ} \mathrm{C}$ & $0.08 \mathrm{~B}$ & $0 \mathrm{~B}$ & $0.08 \mathrm{~B}$ & 0B \\
\hline $1550^{* *}$ & 99.0 & 99.6 & 55.2 & 51.1 \\
1600 & 99.6 & 99.6 & 73.9 & 58.8 \\
1650 & 99.3 & 99.3 & 96.0 & 94.8 \\
\hline
\end{tabular}

*Theoretical density of the samples is calculated to be $3.31 \mathrm{~g} \mathrm{~cm}^{-3}$.

** Holding time of the SPS samples was $10 \mathrm{~min}$ at $1550{ }^{\circ} \mathrm{C}$ and $5 \mathrm{~min}$ at 1600 and $1650{ }^{\circ} \mathrm{C}$. 
Fig. 1 Shrinkage curve of SPS samples at: (a), $1550{ }^{\circ} \mathrm{C}$; (b), $1600{ }^{\circ} \mathrm{C}$; and (c), $1650{ }^{\circ} \mathrm{C}$. Fig. 2 SEM images of SPS samples (0.08B) at: (a), (b), $1550{ }^{\circ} \mathrm{C}$; (c), (d), $1600{ }^{\circ} \mathrm{C}$; and (e), (f), $1650{ }^{\circ} \mathrm{C}$.

Fig. 3 Thermal conductivity of SPS samples (0.08B). 


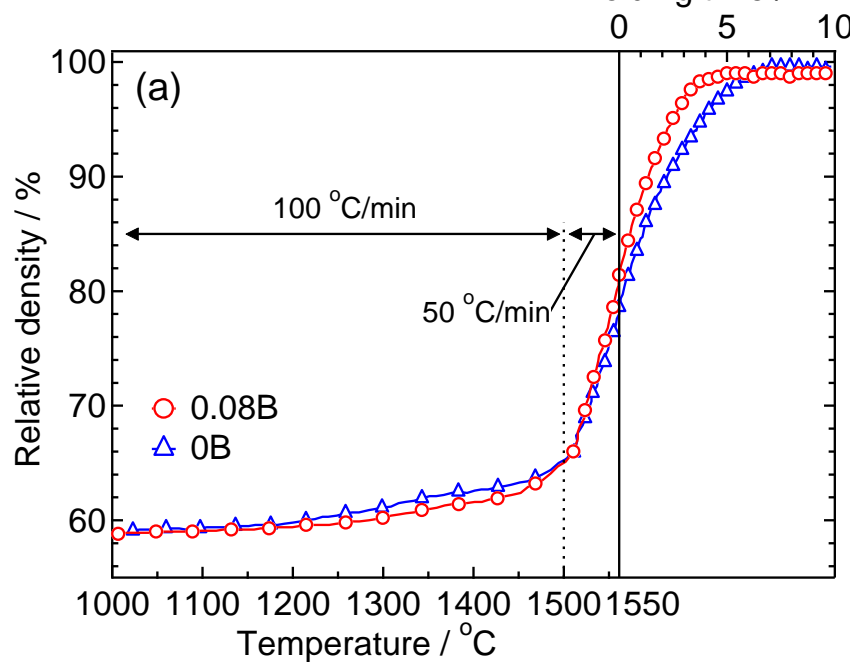

Holding time / $\mathrm{min}$

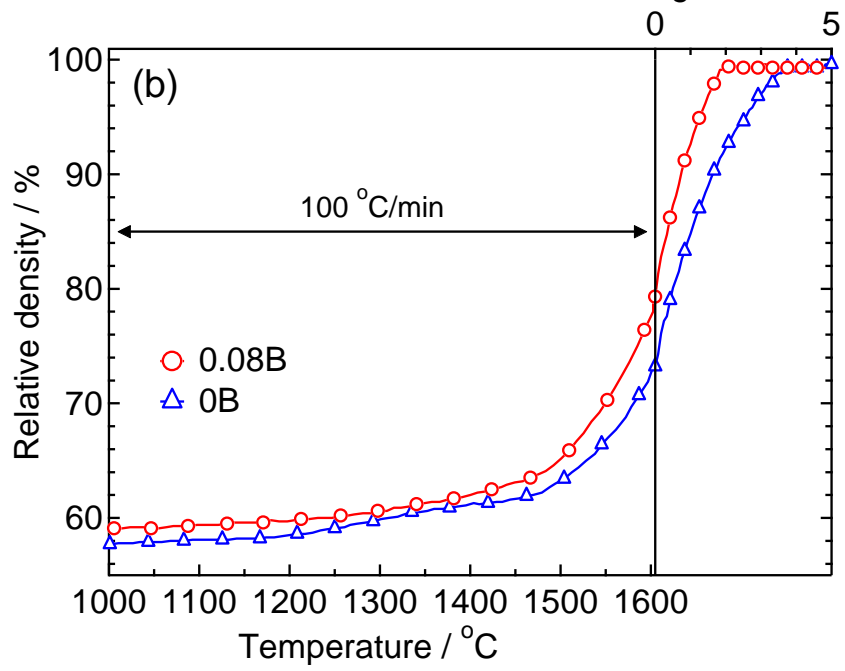

Holding time / $\mathrm{min}$

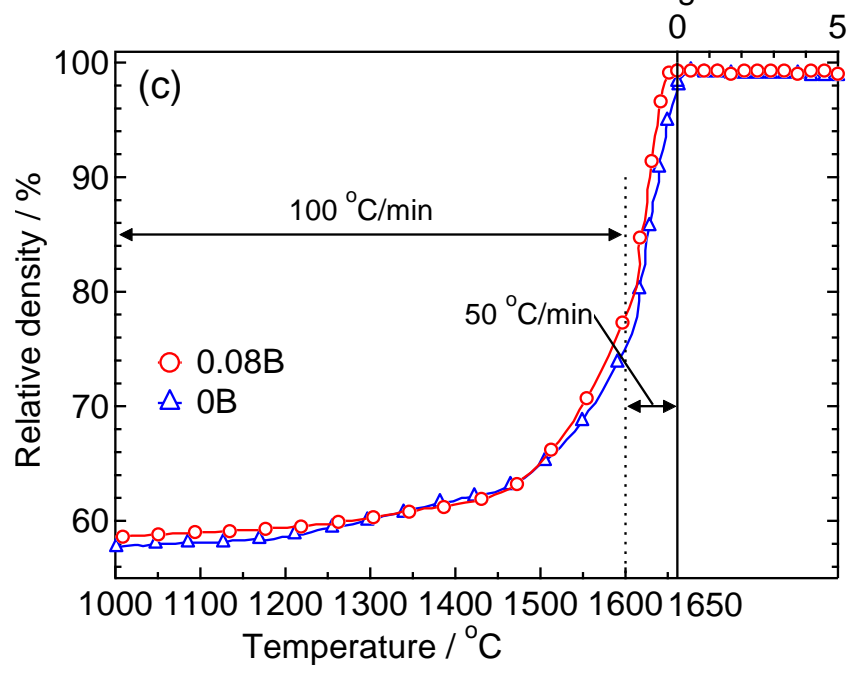

Fig. 1 Shrinkage curve of SPS samples SPSed at: (a), $1550^{\circ} \mathrm{C}$; (b), $1600^{\circ} \mathrm{C}$; and (c), $1650^{\circ} \mathrm{C}$. 


\section{(a)}

(b)
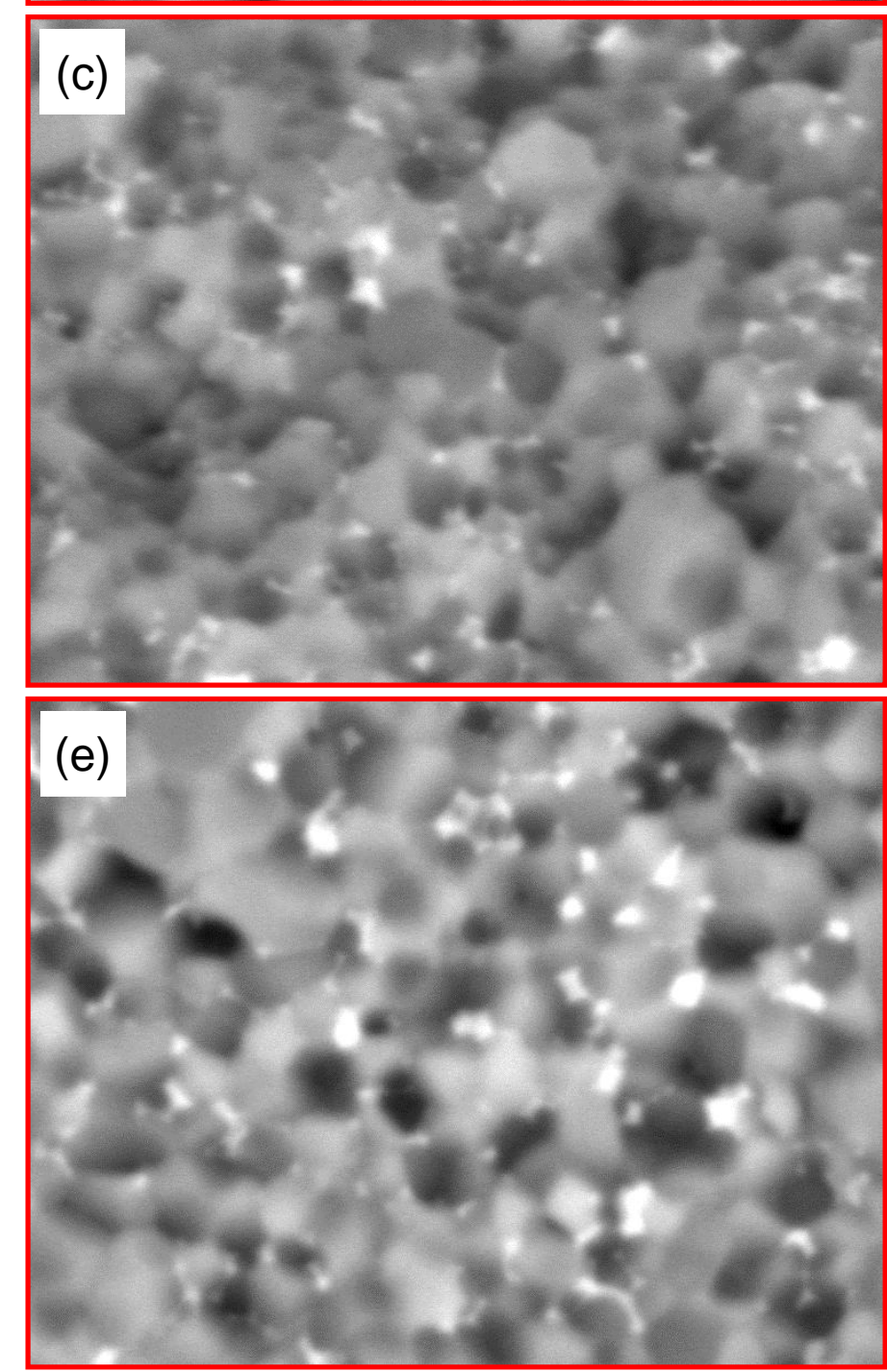

Backscattered image

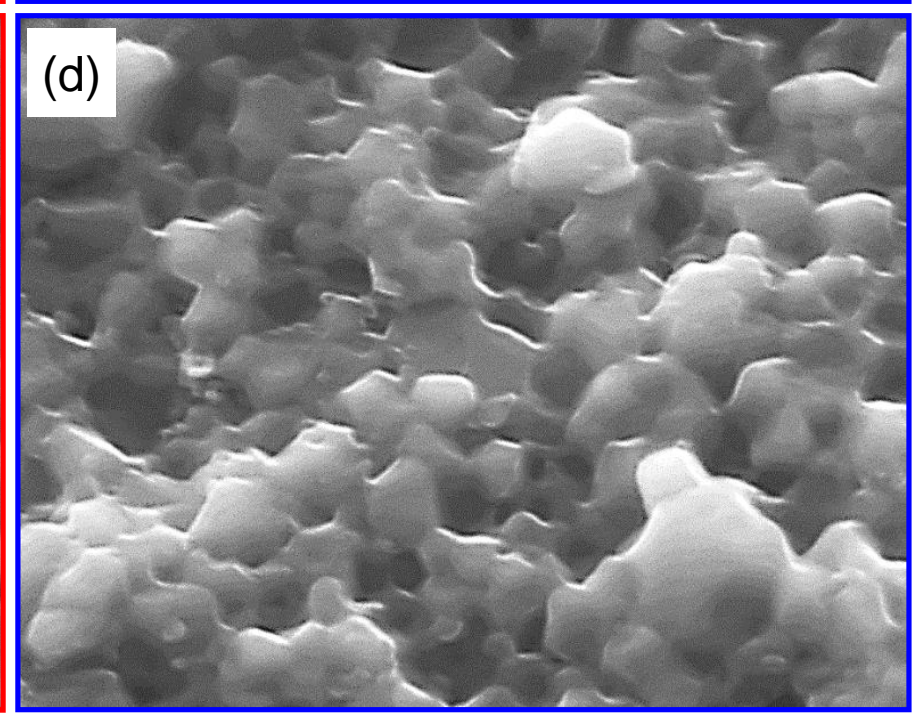

(f)

Secondary electron image

Fig. 2 SEM images of SPS samples (0.08B) at: (a), (b), $1550^{\circ} \mathrm{C}$; (c), (d), $1600^{\circ} \mathrm{C}$; and (e), (f), $1650^{\circ} \mathrm{C}$. 


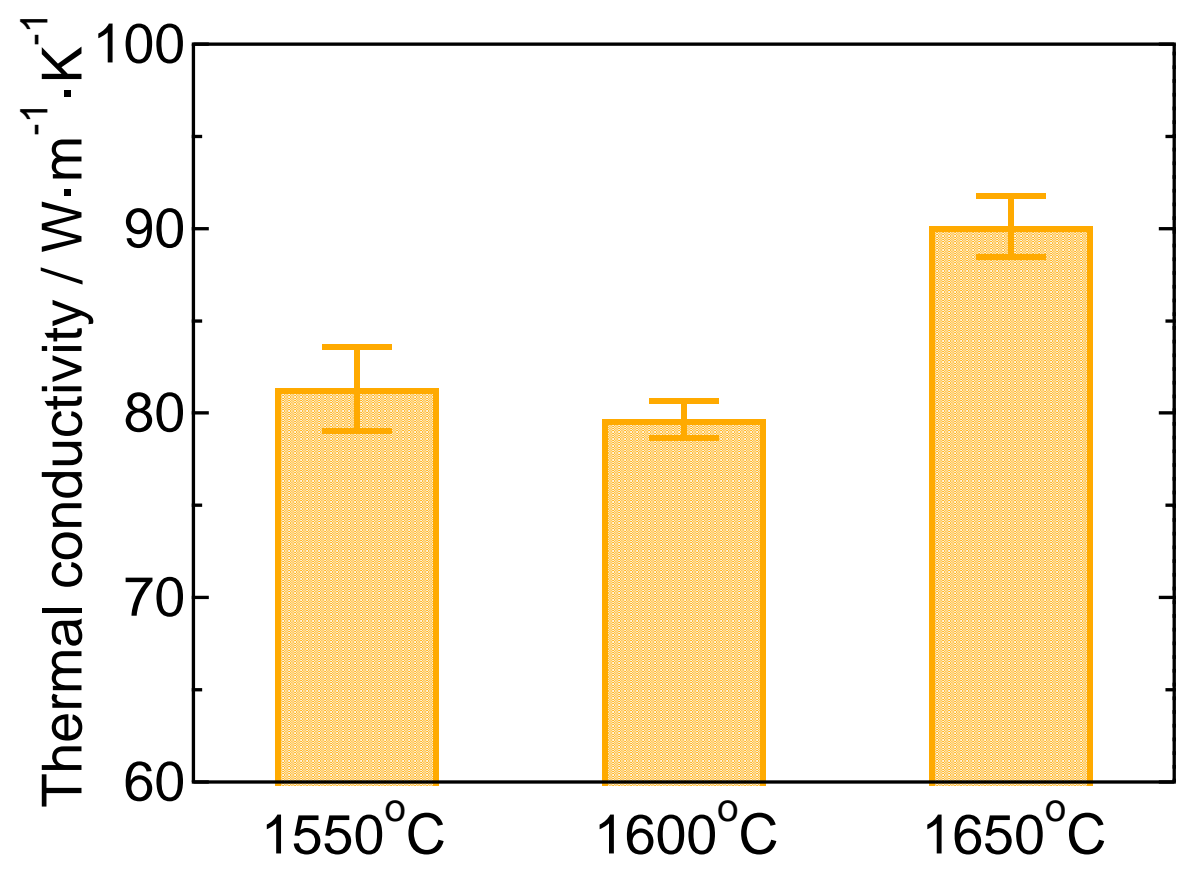

Fig. 3 Thermal conductivity of SPS samples (0.08B) . 